\title{
Judicialização da saúde: propostas de racionalização
}

Health's judicialization: rationalization proposals

Judicialización de la salud: propuestas de racionalización

\author{
Celia Cristina Dal Moro ${ }^{1}$ \\ Laura Dal Moro² \\ Raquel Randow ${ }^{3}$ \\ Keli Bahia Felissícimo Zocratto ${ }^{4}$
}

\section{Resumo}

Objetivo: o levantamento e análise de trabalhos, sobre propostas de racionalização da judicialização da saúde no Brasil. Metodologia: foi feito levantamento bibliográfico na base de dados da Biblioteca Virtual de Saúde, usando descritores compatíveis com a pesquisa. Resultados: foram encontrados 99 trabalhos com a temática proposta, sendo que apenas 28 apresentavam propostas de racionalização da judicialização da saúde. Conclusão: ainda é baixa a produção intelectual brasileira para a racionalização da judicialização da saúde no Brasil.

Palavras-chave: Judicialização da saúde. Decisões judiciais. Racionalização.

\begin{abstract}
Objective: the collection and analysis of works on proposals for rationalization of health judicialization in Brazil. Methodology: a bibliographic survey was made in the Virtual Health Library database using descriptors compatible with the research. Results: 99 studies were found with the proposed theme, of which only 28 presented proposals for rationalization of health judicialization. Conclusion: the Brazilian intellectual production for the rationalization of health judicialization in Brazil is still low.
\end{abstract}

Keywords: Judicialization of health. Judicial decisions. Rationalization.

\section{Resumen}

Objetivo: el levantamiento y análisis de trabajos, sobre propuestas de racionalización de la judicialización de la salud en Brasil. Metodología: se realizó un levantamiento bibliográfico en la base de datos de la Biblioteca Virtual en Salud, usando descriptores compatibles con la investigación. Resultados: se encontraron 99 trabajos de con la temática propuesta, siendo que sólo 28 presentaban propuestas de racionalización de la judicialización de la

\footnotetext{
${ }^{1}$ Gestora de Serviços de Saúde, Universidade Federal de Minas Gerais, Escola de Enfermagem, Belo Horizonte, Minas Gerais, Brasil. E-mail: celiadalmoro@gmail.com

${ }^{2}$ Bacharel em Direito, Faculdade de Direito Milton Campos, Belo Horizonte, Minas Gerais, Brasil. E-mail: lauradalmorof@gmail.com

${ }^{3}$ Mestranda em Demografia, Universidade Federal de Minas Gerais, Escola de Enfermagem, Belo Horizonte, Minas Gerais, Brasil. Orcid: https://orcid.org/0000-0002-6086-7939 E-mail: raquelrandowb@gmail.com

${ }^{4}$ Doutora em Saúde Pública. Professora adjunta do curso de Gestão de Serviços de Saúde, Universidade Federal de Minas Gerais, Escola de Enfermagem, Belo Horizonte, Minas Gerais, Brasil. E-mail: kelibahia@yahoo.com.br.
} 
salud. Conclusión: aún es baja la producción intelectual brasileña para la racionalización de la judicialización de la salud en Brasil.

Palabras clave: Judicialización de la salud. Decisiones judiciales. Racionalización.

\section{Introdução}

O financiamento das políticas públicas de saúde no Brasil é responsabilidade do Estado assegurado pela Constituição Federal de 1988, que reconheceu a saúde como direito de todos e dever do Estado (1). Para tanto, foi criado um Sistema Único de Saúde (SUS) com o objetivo de atender as demandas de saúde da população dentro dos princípios da universalidade, integralidade e equidade (2). Esse direito deverá ser garantido mediante políticas sociais e econômicas que visem à redução do risco de doença e de outros agravos e ao acesso universal e igualitário às ações e serviços para promoção, proteção e recuperação da saúde (1).

A saúde, por ser um direito fundamental e social do ser humano, tem motivado inúmeras ações judiciais e, consequentemente, vem desorganizando o orçamento público e provocando instabilidade no planejamento e financiamento dos serviços de saúde (3-6). Também tem acarretado constantes alterações na execução das políticas públicas de saúde, devido à necessidade da realocação dos recursos financeiros para atender as decisões do Poder Judiciário em favor dos que o procuram (6-7).

Essa transferência de poder para juízes e tribunais, quando acontece de maneira exacerbada, é denominada judicialização da saúde (4). Nesse contexto, é diversa a análise do direito à saúde quando realizada sob a ótica do Direito ou das Políticas Públicas. O primeiro foca o poder decisional entre direito/não-direito, enquanto que as políticas públicas alternam entre poder/não-poder (8).

Atualmente, encontra-se consolidada a via judicial para a garantia do direito à saúde, reforçando o ponto de vista da apropriação individual do que é coletivo (9). A primazia do direito individual em prejuízo do direito coletivo não é correta, pois não se deve fazer uma garantia para um cidadão ao custo de prejudicar inúmeras pessoas, por meio da desorganização do gasto público e da falta de limite para exercer o direito à saúde (3), (5).

Nos últimos 10 anos, ao analisar os argumentos emitidos pelo Supremo Tribunal Federal (STF) em relação ao direito à saúde, conclui-se que não existem critérios relacionados a nenhuma teoria de justiça para a distribuição de recursos no cumprimento das decisões judiciais. Ao realizar a microjustiça, que traz soluções individualizadas, deixa-se de 
praticar a macrojustiça, que não despreza as implicações dessas decisões à coletividade (10).

As demandas judiciais também podem indicar as condições de oferta de serviços de saúde da população e como as políticas para o futuro devem ser pensadas e planejadas alterando seu curso atual (9), (11-12). Entretanto, questiona-se se o avanço do Judiciário na efetivação do direito a saúde estaria contribuindo para a consolidação do SUS ou produzindo efeitos colaterais a partir de suas decisões (13-14).

O direito à saúde e o orçamento caminham juntos e para que as políticas públicas de saúde possam ser efetivadas é necessário respeitar as normas orçamentárias. Quanto às decisões judiciais, o equilíbrio e a proporcionalidade serão indispensáveis para que não ocorra o prejuízo da concretização da política de saúde planejada, ambas dependentes do financiamento do Estado para a consolidação do direito à saúde (15).

Diversas localidades brasileiras fizeram estudos para quantificar os valores pagos com demandas judiciais em saúde e verificaram um constante aumento nesse custo (1621). Os vultosos valores identificados nas pesquisas, certamente estão subestimados, visto que não incluem o custo pago pelo Estado para a manutenção da máquina pública na resolução dessas demandas, como ficou demonstrado na análise do perfil da judicialização da saúde em alguns estados brasileiros (22).

Qualquer valor utilizado com a judicialização da saúde não pode desconsiderar os gastos com a manutenção da máquina pública na resolução dessas demandas. Isso ficou demonstrado no relatório do Conselho Nacional de Justiça (CNJ), ao avaliar o perfil da judicialização da saúde nos estados de São Paulo, Paraná, Rio Grande do Norte, Minas Gerais, Mato Grosso do Sul e Acre. Foram avaliadas as despesas dos tribunais, ou seja, os gastos com recursos humanos; infraestrutura e prestação de serviços; além da quantidade de servidores efetivos que atuam nesses tribunais, a carga horária trabalhada e quantos processos, em média, cada um deles julgou (22).

Outros trabalhos ressaltam a urgência de um debate entre os atores sociais e os três Poderes quanto à racionalização dos recursos escassos (16-17).

O termo racionalização refere-se ao processo da introdução de racionalidades ou do que julgamos ser racional em diferentes épocas e lugares. Essas ações, racionalmente orientadas, derivam da racionalidade instrumental definida por Weber com referência a regras, regulamentos e leis (23). 
Nota-se um despertar dos atores em busca de soluções que minimizem gastos, por meio da racionalização da judicialização, sem ferir a ética e o direito. Essas propostas buscam a efetividade na resolução dessas demandas, utilizando-se de estratégias extrajudiciais e judiciais com o objetivo de preservar as políticas públicas, fim precípuo do direito à saúde (17), (20), (24).

Algumas experiências de sucesso, na efetivação do direito à saúde, puderam ser conhecidas por um estudo multicêntrico desenvolvido pelo CNJ. No relatório, foram apresentadas experiências de estratégias extrajudiciais, judiciais ou ambas, a despeito das diferenças entre os arranjos institucionais específicos (22).

Manifestou-se o interesse em fazer uma pesquisa bibliográfica sobre as possíveis propostas de racionalização da judicialização da saúde, com a finalidade de conhecer o estado da arte de estudos com a temática no país.

\section{Metodologia}

Foi realizada uma revisão integrativa de literatura, em periódicos científicos do acervo da Biblioteca Virtual em Saúde (BVS), com coleta de dados realizada a partir de fontes secundárias.

O estudo seguiu as seis etapas de elaboração: escolha da questão norteadora; busca na literatura; definição dos critérios de inclusão; avaliação dos estudos incluídos nos resultados; discussão dos resultados; e apresentação da revisão inte-grativa (26).

As propostas sugeridas para a racionalização da judicialização da saúde no Brasil foram a questão norteadora da pesquisa. Foram combinados, por meio do operador de pesquisa (booleano) AND na Biblioteca Virtual em Saúde (BVS), os descritores: 1) judicialização da saúde e decisão judicial; 2) judicialização da saúde e protocolo; e 3) judicialização da saúde e diretrizes. Considerando, como critério de inclusão, apenas os artigos publicados a partir de 2009, foram encontrados, respectivamente, 109 estudos para os descritores 1; 5 estudos para o 2; e 26 estudos para o 3 (ver Figura 1).

Dos artigos selecionados, foram coletadas as seguintes informações: objetivos, método do estudo e os principais resultados encontrados. 
Figura 1. Fluxograma de análise dos artigos

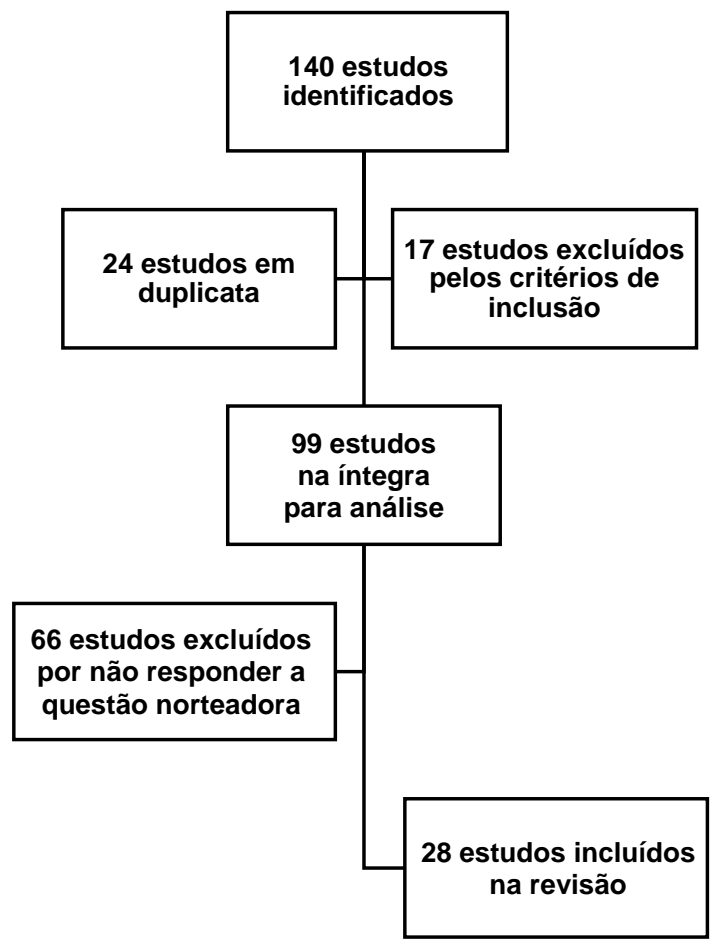

Fonte: Dados obtidos de artigos segundo a metodologia de revisão do estudo.

\section{Resultados e discussão}

Dentre as publicações encontradas (ver Quadro 1), a maioria refere-se ao ano de 2015, que contabiliza sete publicações; em 2013, 2010, 2017 e 2016, foram quatro artigos; em 2014, foram três; e, nos anos de 2012 e 2010, foram selecionados dois trabalhos. Com relação ao tipo de publicação, foram encontrados 23 artigos, duas dissertações de mestrado, duas teses de doutorado e uma dissertação de pós-graduação strictu sensu. Das nove revistas que veicularam trabalhos sobre o tema, a maioria foi publicada na Revista de Direito Sanitário, seguida pelos Cadernos Ibero-Americanos de Direito Sanitário. Os autores recorrentes foram Felipe Asensi, Tereza Robichez de Carvalho, Vera Lúcia Edais Pepe e Miriam Ventura.

A judicialização da saúde é um tema complexo, de modo que a maioria dos autores indica mais de uma proposta para o seu controle. Dentre as categorias sugeridas, encontramos as propostas judiciais que se utilizam de estratégias formais para apoiarem as decisões dos magistrados, como as fornecidas pelo Núcleo de Avaliação de Tecnologias em Saúde (NATS), citado em alguns trabalhos (16), (20). 
O NATS foi instituído em Hospitais de Ensino e teve como objetivo fornecer análises sobre novas tecnologias e processos, e sua possível incorporação resultante da análise do seu valor clínico por meio da medicina baseada em evidências (MBE). Em uma dessas análises, o objetivo foi amparar as decisões judiciais por meio da emissão de notas técnicas (NT) e os resultados mostraram uma redução dos gastos do poder público com a judicialização da saúde, bem como a necessidade de contínuo processo de integração entre os atores da judicialização, sendo o NATS um mediador neutro nesse processo (20). Os magistrados do estado do Mato Grosso solicitaram o parecer técnico do Núcleo de Apoio Técnico $\left(\mathrm{NAT}^{5}\right)$, instalado no Fórum, para auxiliar nas questões judiciais envolvendo a saúde pública. Nessas análises, o NAT considerou pertinente apenas $50 \%$ das ações, no ano de 2011; e 34\% das ações em 2012, não encontrando respaldo legal para o restante das ações. No entanto, esses pareceres foram citados em 84\% e 94\% dos processos em 2011 e 2012, respectivamente. Os autores sugerem ainda um debate coletivo com os atores sociais e os três Poderes para conhecer as políticas públicas existentes, fomentar o controle social da população, cobrar políticas eficazes e gestão eficiente (16).

Outra proposta judicial de racionalização da judicialização da saúde seria a utilização dos Protocolos Clínicos e Diretrizes Terapêuticas (PCDTs) pelo SUS (24-25). Com a adoção dos PCDTs como parâmetro, existe uma maior segurança na decisão analisada, ao fornecer argumentos técnico-políticos baseados em evidências científicas e favorecer as distribuições de bens e recursos de saúde, apesar de seu conteúdo poder ser questionado judicialmente (24).

Em uma análise bem detalhada sobre diversas propostas para o enfrentamento da judicialização da saúde, incluindo os PCDTs, verifica-se a importância de garantir o atendimento das demandas individuais, considerando a legislação sanitária vigente. Nesse sentido, dever-se-ia exigir o ingresso na rede pública e considerar os protocolos clínicos e relações de medicamentos. Com isso, minimizam-se os efeitos negativos da desenfreada judicialização de saúde, impedindo a banalização do caminho judicial e promovendo a consolidação do SUS (25).

Ao se acreditar que sempre existirá uma política pública correspondente às patologias, e com a restrição das ações individuais somente a medicamentos e produtos sanitários

\footnotetext{
${ }^{5}$ O Núcleo de Apoio Técnico (NAT), criado pelo Tribunal de Justiça do Estado de Mato Grosso/TJMT em parceria com a Secretaria Estadual de Saúde/SESMT, tem como escopo dar suporte técnico aos juízes e desembargadores nos processos de demandas na área da saúde. É composto por médicos e farmacêuticos cedidos para o TJMT.
} 
previstos pelo SUS, a atualização dos protocolos clínicos seria apenas por meio de ações civis públicas ou coletivas. Assim, os arranjos institucionais locais poderiam ser igualmente decisivos na construção e efetivação compartilhada do direito à saúde, mas esse posicionamento dependeria do amadurecimento cultural da população (17), (25), (27).

O equilíbrio e a racionalidade previstos na teoria da reserva do possível seriam também uma maneira do Judiciário pautar suas decisões diante da escassez de recursos (15). No entanto, a fixação desses limites não deveria considerar apenas o custo do que está sendo pleiteado, mas também sua correspondência com a política pública vigente formulada para as necessidades de saúde da população, dentro dos parâmetros de recursos disponíveis (28).

Outra categoria sugerida pela maioria dos autores são as propostas extrajudiciais que, diferentemente das judiciais, têm um caráter preventivo, são heterogêneas e se utilizam de estratégias informais ou formais na redução das demandas judiciais (13), (16-17), (19-21), (25), (27), (29-46).

Uma dessas propostas extrajudiciais seria em relação ao constante aumento de gastos com medicamentos. As melhorias na gestão da assistência farmacêutica (AF) - maior conhecimento do Judiciário, da classe médica e da população sobre os programas e normas técnicas da AF do SUS e a existência de um suporte técnico para auxiliar no entendimento das questões de saúde - seriam um apoio importante para a minimização desses gastos (33-34), (41).

Em um trabalho nos municípios do estado do Mato Grosso do Sul com o objetivo de analisar as demandas judiciais por medicamentos e suas consequências, entre os anos de 2008 e 2011, verificou-se muitas dificuldades na gestão da AF, dentre outras causas. Os problemas encontrados nos municípios variaram de um extremo a outro, como a compra excessiva e sem planejamento de medicamentos para se evitar a judicialização, bem como muitas ações judiciais para se ter acesso à medicamentos que deveriam ser disponibilizados pelo SUS. Para o enfrentamento desses problemas, foi sugerida a adoção de uma verdadeira relação de medicamentos essenciais, sempre baseada em evidências e com o apoio dos médicos, gestores e população (41).

Outra medida importante seria melhorar a organização e o gerenciamento dos estoques de medicamentos padronizados do SUS, otimizando a compra e aplicação dos recursos escassos e, consequentemente, evitando a existência de pleitos por essas causas 
previsíveis (33). Assim, a melhoria na qualidade da AF e de seus serviços daria legitimidade e esclareceria, para a sociedade e judiciário, que a negativa de seus pleitos seria em virtude da necessidade da alocação racional de recursos escassos sem, no entanto, ignorar os devidos cuidados com a população (34).

A atualização constante da lista oficial de medicamentos do SUS também é uma recomendação apresentada por diversos autores (33), (42), (44). É frequente a demanda por medicamentos não padronizados pelo SUS. Independente dos protocolos e lista de medicamentos essenciais, como os pleiteados nos primeiros sete meses de 2017 no Distrito Federal. Entre eles, estavam alguns não registrados na Agência Nacional de Vigilância Sanitária (Anvisa) e outros ainda não presentes na lista disponibilizada pelo SUS. O trabaIho de Magalhães (33) sugeriu a constante atualização dos protocolos e das listas do SUS que, além de reduzir possíveis demandas judiciais, funcionaria como instrumento na compra de medicamentos de forma planejada e segura, com a otimização dos recursos escassos.

Outros resultados semelhantes foram encontrados nos municípios do estado da Bahia, no período de 2006 a 2010, sendo que grande parte dos medicamentos solicitados via judicialização não constavam nos programas da AF do SUS. Além disso, as solicitações eram sem análises técnicas e, muitas delas, referentes a medicamentos que deveriam estar disponíveis para a população. Isso confirma a necessidade de melhoria na gestão, financiamento e atualização dos protocolos, com a inclusão de novas patologias, permitindo constantes revisões nas políticas públicas de AF e com a incorporação de novas tecnologias no SUS (18).

A medicina baseada em esperança, que utiliza medicamentos fora de sua indicação ou experimentais e sem registro na Anvisa, coloca em risco quem a utiliza e prejudica a coletividade à medida que são tecnologias de alto custo para o Estado (42). Importante analisar as relações perigosas existentes entre o setor farmacêutico e associações representativas de portadores de doenças. Muitas vezes, iludidos pela possibilidade de cura e influenciados pela indústria farmacêutica, esses indivíduos tentam obter medicamentos pela via judicial sem refletir sobre o uso crítico e responsável desses fármacos (44).

Diante de tantos problemas que envolvem a judicialização, uma oportunidade importante relatada pelos autores foi a audiência pública convocada pelo STF em 2009 (32), (42). Na oportunidade, representantes de vários grupos envolvidos na judicialização da 
saúde debateram sobre os aspectos jurídicos, administrativos e terapêuticos, mas não aprofundaram sobre as necessidades identificadas pelos setores envolvidos na busca de soluções (32). No entanto, após a audiência pública, ficou constatado um mútuo aprendizado entre os sistemas político e jurídico, ao utilizarem os argumentos discutidos na audiência pública em $20 \%$ das decisões judiciais. As medidas de maior impacto foram sobre 0 uso de evidência científica pelo Judiciário e Executivo e a sustentabilidade do financiamento da saúde. Quando há uma definição do que é considerado gasto na saúde e qual é a vinculação mínima desse recurso, a sustentabilidade do financiamento da saúde fica resguardada, gerando a expectativa de mais recursos para que os gestores possam desenvolver as políticas públicas (42).

Para a maioria dos autores, a solução compartilhada e dialogada também é um caminho seguro na tomada de decisões que envolvem a judicialização da saúde (16-17), (1920), (25), (30), (34-37), (39), (46). Dentre elas, a mais citada foi a interação estabelecida entre os profissionais da saúde e a justiça. Devido às limitações existentes entre eles, essas práticas inovadoras culminariam em ações pautadas na integralidade e resolutividade, visando à saúde da população. Essas ações poderiam ser estabelecidas por meio de medidas administrativas e judiciais para favorecer uma resolução extrajudicial, bem como uma maior capacitação do judiciário por meio de um suporte técnico em AF. Tal medida também poderia ser expandida para a população médica em relação aos programas de $A F$ existentes no SUS (25), (30), (35), (39).

Outros destacam a importância de uma atuação unificada entre o poder público e a população no levantamento das necessidades e metas (19). Entre as resoluções demandista ou resolutivas, esta última é mais indicada por permitir uma solução dialogada com a participação de todos os atores, auxiliando o Ministério Público na defesa do direito à saúde (37).

Um diálogo institucional entre o Executivo e Judiciário, no que se refere às políticas públicas de saúde foi também sugerido (17). Foi salientada a importância de uma constante integração entre os atores sociais envolvidos na judicialização da saúde, ou seja, magistrados, operadores do direito, gestores, pacientes, profissionais da saúde e indústria farmacêutica (20), (46).

O debate coletivo, entre o Legislativo, Executivo e Judiciário com os atores sociais, sobre a questão da ineficiência na gestão da saúde seria uma medida importante para con- 
ter 0 avanço das ações judiciais. A ampliação desse debate se faz necessário, a fim de efetivar a saúde por meio de políticas públicas eficazes e com o controle social dessas ações pela população (16).

Como não existe uma única solução para o problema, espera-se que, por meio da discussão, possam ser adotados parâmetros racionais visando uma forma rápida e justa na resolução dos problemas, sendo o diálogo fundamental para todos os envolvidos (34), (36).

A inclusão da disciplina de Direito Sanitário nos cursos preparatórios para concursos dirigidos a magistratura, além de seminários direcionados aos gestores, Ministério Público e magistrados, incluindo visitas aos Conselhos Municipais e Estaduais de Saúde, são medidas indicadas para maior entrosamento sobre a matéria e uma forma de questionar o modo litigioso adversarial de se operar o direito (29), (38).

Outros caminhos para conter a judicialização da saúde são sugeridos e, entre eles, estão os comitês de mediação, de bioética e administrativos do SUS (13), (21), (25), (29), (31), (39), (43).

No nordeste do Brasil, um estudo identificou uma baixa procura pela Justiça quando foi feita a avaliação do grau de satisfação dos usuários de um serviço de saúde públicoprivado em convênio com o SUS. Após análises, o estudo concluiu que esses resultados foram decorrentes do baixo grau de escolaridade e desconhecimento da população sobre o direito à saúde. Os autores acreditam que a melhora do grau de satisfação pode reduzir a judicialização e que os usuários com mais conhecimento, por serem mais exigentes, recorrem com mais frequência à Justiça (43). Nesses casos, recomendam soluções alternativas como a justiça restaurativa e a mediação, previamente ao ajuizamento de uma ação judicial, com a possibilidade de uma resolução pacífica e sem a presença de juízes e tribunais (29), (43).

No entanto, esta realidade não retrata o que acontece em muitas localidades do país, onde poderiam apresentar baixos índices de judicialização caso os médicos, os gestores e a população estivessem mais preparados para enfrentar a situação. Os responsáveis pela gestão da saúde municipal vivenciam graves problemas envolvendo a ética, a equidade e a justiça distributiva (21). Assim, apoiados pelas instituições universitárias, os comitês intermunicipais e multiprofissionais de bioética auxiliariam, com a aplicação desses princípios, na distribuição dos recursos escassos destinados à saúde (21), (29), (43). 
As mudanças administrativas no SUS, com o objetivo de minimizar a judicialização, se instituídas, representariam uma possibilidade prévia em que usuários insatisfeitos pudessem recorrer antes de ingressar com ações judiciais (39). Uma das mudanças seria a criação de centros de triagem farmacêutica, compostos por médicos e farmacêuticos que tivessem conhecimento do SUS, bem como a avaliação técnica de especialistas para os casos encaminhados pelas câmaras de conciliação (25). A construção de um mapa de conflito no âmbito do SUS seria também outra forma do sistema operar, ao antever e solucionar os possíveis problemas futuros por meio de vigilância permanente (29).

$\mathrm{Na}$ tentativa de reduzir os efeitos colaterais das decisões do Judiciário nas políticas públicas do SUS, foram recomendadas diferentes soluções e uma delas seria a inclusão do Judiciário no Pacto de Gestão do SUS (13). As evidências científicas também auxiliariam na formulação eficiente das políticas públicas, servindo como parâmetros de monitoramento no uso racional das tecnologias ou medicamentos, sem a necessidade de intervenção judicial (31).

Aconselham-se estudos referentes às diferentes decisões dos tribunais de justiça com o objetivo de compreender as características regionais na prestação dos serviços públicos, bem como os valores e concepções utilizados pelos juízes em seus julgamentos (45). A criação de instrumentos operacionais de comunicação, entre os setores e atores envolvidos, com a constante atualização dos dados sobre as demandas judiciais e disponibilizados em linguagem acessível, poderia estimular novas ações inovadoras com experiências positivas de racionalização (39).

Nos anos de 2013 e 2014, foi feita uma pesquisa, em parceria com o CNJ, para conhecer algum tipo de experiência inovadora desenvolvida nos tribunais do Brasil objetivando a efetivação do Direito à Saúde (17). Assim, ficou conhecida a experiência no município de Lages (SC) que foi exitosa ao conseguir mobilizar atores jurídicos e políticos e criar estratégias extrajudiciais. Ao promover a mútua capacitação profissional, feita de maneira informal, entre juízes, gestores e profissionais da área da saúde, foi se estabelecendo o diálogo institucional que apresentou diversos ganhos para os profissionais envolvidos, bem como a redução das demandas judiciais. Assim, à medida que as resoluções extrajudiciais atingiam o objetivo inicial da experiência, que era racionalizar o uso do modelo adversarial do Judiciário, os direitos do cidadão eram preservados e os resultados esperados foram obtidos mais rapidamente do que na justiça comum (17). 


\section{Quadro 1. Seleção dos artigos com propostas para a racionalização da judicialização en-} contrados na pesquisa

\begin{tabular}{|c|c|c|c|}
\hline $\begin{array}{l}\text { Autores, título, } \\
\text { periódico e ano }\end{array}$ & Objetivo(s) & Método(os) & $\begin{array}{l}\text { Principais } \\
\text { resultados encontrados }\end{array}$ \\
\hline $\begin{array}{l}\text { Nogueira JL, Carvalho L, Dadalto } \\
\text { L. Parcerias entre Universidades } \\
\text { e Poder Judiciário: experiência } \\
\text { de Minas Gerais. Cadernos ibe- } \\
\text { ro-americanos de direito sanitá- } \\
\text { rio. } 2017\end{array}$ & $\begin{array}{l}\text { Apresentar a parceria } \\
\text { entre o NATS com o Tri- } \\
\text { bunal de Justiça para } \\
\text { emissão de Notas Técni- } \\
\text { cas. }\end{array}$ & Estudo de caso & $\begin{array}{l}\text { Necessidade de contínuo processo de } \\
\text { integração entre atores que compõe a } \\
\text { judicialização da saúde e o NATS, } \\
\text { podendo ser um ator neutro. }\end{array}$ \\
\hline $\begin{array}{l}\text { Arruda, SC. Análise sobre a judi- } \\
\text { cialização da saúde no estado de } \\
\text { mato grosso no período de } 2011 \text { - } \\
\text { 2012. Cadernos lbero- } \\
\text { Americanos de Direito Sanitário. } \\
2017\end{array}$ & $\begin{array}{l}\text { Compreender o fenômeno } \\
\text { da Judicialização do } \\
\text { acesso à Saúde no Mato } \\
\text { Grosso. }\end{array}$ & $\begin{array}{l}\text { Método } \\
\text { qualitativo e } \\
\text { quantitativo }\end{array}$ & $\begin{array}{l}\text { O problema da saúde no estado de } \\
\text { Mato Grosso está longe de ser resolvi- } \\
\text { do. A cada dia a demanda de ações } \\
\text { envolvendo a saúde cresce no Fórum } \\
\text { da Capital. }\end{array}$ \\
\hline $\begin{array}{l}\text { Verbicaro LP, Santos ACV. A } \\
\text { necessidade de parâmetros para } \\
\text { a efetivação do direito à saúde: a } \\
\text { judicialização do acesso ao hor- } \\
\text { mônio do crescimento no estado } \\
\text { do Pará. Revista de Direito Sani- } \\
\text { tário. } 2017\end{array}$ & $\begin{array}{l}\text { Analisar efeitos da judicia- } \\
\text { lização do acesso ao } \\
\text { medicamento com base } \\
\text { na medida liminar que } \\
\text { determinou o fornecimen- } \\
\text { to de medicamentos para } \\
\text { todas as crianças. }\end{array}$ & $\begin{array}{l}\text { Pesquisa } \\
\text { descritiva }\end{array}$ & $\begin{array}{l}\text { Necessidade da aplicação de parâme- } \\
\text { tros técnicos que levem em considera- } \\
\text { ção critérios sanitários da legislação } \\
\text { vigente na condução de ações judiciais } \\
\text { envolvendo saúde, para otimizar e } \\
\text { ganhar eficiência nos gastos públicos e } \\
\text { direitos sociais. }\end{array}$ \\
\hline $\begin{array}{l}\text { Duarte CS, Braga PVB. A Utili- } \\
\text { zação dos Protocolos Clínicos e } \\
\text { Diretrizes Terapêuticas e a Raci- } \\
\text { onalização da Judicialização do } \\
\text { Direito à Saúde. Revista de Direi- } \\
\text { to Sanitário. } 2015\end{array}$ & $\begin{array}{l}\text { Analisar a adoção dos } \\
\text { PCDTs como parâmetro a } \\
\text { ser utilizado pelos tribu- } \\
\text { nais nas ações cujo obje- } \\
\text { to são prestações de } \\
\text { natureza positiva voltadas } \\
\text { à efetivação do direito à } \\
\text { saúde. }\end{array}$ & $\begin{array}{l}\text { Pesquisa } \\
\text { documental }\end{array}$ & $\begin{array}{l}\text { Tal referencial auxilia juízes a decidir } \\
\text { as demandas judiciais de fornecimento } \\
\text { de medicamentos, garantindo preva- } \\
\text { lência da racionalidade prevista pelo } \\
\text { formulador das políticas públicas corre- } \\
\text { latas, e a utilização de argumentos } \\
\text { técnico-políticos na distribuição de } \\
\text { recursos de saúde. }\end{array}$ \\
\hline $\begin{array}{l}\text { Silva Junior GB, Dias ER. Avalia- } \\
\text { ção da satisfação dos usuários } \\
\text { de um serviço de saúde público- } \\
\text { privado no nordeste do Brasil e a } \\
\text { judicialização da saúde. Revista }\end{array}$ & $\begin{array}{l}\text { Analisar o grau de satisfa- } \\
\text { ção dos usuários do ser- } \\
\text { viço público-privado de } \\
\text { saúde, bem como o nível } \\
\text { de conhecimento sobre }\end{array}$ & $\begin{array}{l}\text { Estudo } \\
\text { transversal }\end{array}$ & $\begin{array}{l}\text { Os usuários se mostraram satisfeitos } \\
\text { com os serviços oferecidos, conside- } \\
\text { rando bom ou excelente. Baixa procura } \\
\text { pelo Judiciário para questões ligadas à } \\
\text { saúde, o que pode decorrer da baixa }\end{array}$ \\
\hline
\end{tabular}


Cuadernos Iberomericanos

de Derecho Sanitario

\begin{tabular}{|c|c|c|c|}
\hline $\begin{array}{l}\text { Autores, título, } \\
\text { periódico e ano }\end{array}$ & Objetivo(s) & Método(os) & $\begin{array}{l}\text { Principais } \\
\text { resultados encontrados }\end{array}$ \\
\hline de Direito Sanitário. 2016 & $\begin{array}{l}\text { seus direitos e a procura } \\
\text { pelo Judiciário para ga- } \\
\text { ranti-los. }\end{array}$ & & $\begin{array}{l}\text { escolaridade e do reduzido grau de } \\
\text { conhecimento de direitos. }\end{array}$ \\
\hline $\begin{array}{l}\text { Asensi F, Pinheiro, R. Judiciali- } \\
\text { zação da saúde e Diálogo Insti- } \\
\text { tucional: A experiência de Lages } \\
\text { (SC). Revista de Direito Sanitá- } \\
\text { rio. } 2016\end{array}$ & $\begin{array}{l}\text { Analisar interação entre } \\
\text { Judiciário, profissionais de } \\
\text { saúde e gestão na efeti- } \\
\text { vação do direito à saúde. }\end{array}$ & $\begin{array}{l}\text { Estudo } \\
\text { multicêntrico }\end{array}$ & $\begin{array}{l}\text { A criação de um padrão comum de } \\
\text { atuação evitou sobreposições e racio- } \\
\text { nalizou os gastos e investimentos. } \\
\text { Houve diálogo do Judiciário com os } \\
\text { gestores de saúde em prol de medidas } \\
\text { efetivas e redução dos conflitos colate- } \\
\text { rais decorrentes da dificuldade de } \\
\text { acesso à saúde pública. }\end{array}$ \\
\hline $\begin{array}{l}\text { Zago B, Swiech LM, Bonamigo } \\
\text { EL, Schlemper Junior BR. As- } \\
\text { pectos bioéticos da judicialização } \\
\text { da saúde por medicamentos em } \\
13 \text { municípios no Meio-Oeste de } \\
\text { Santa Catarina, Brasil. Acta Bio- } \\
\text { ethica. } 2016\end{array}$ & $\begin{array}{l}\text { Estudar a judicialização } \\
\text { da saúde e sua ocorrên- } \\
\text { cia em treze municípios } \\
\text { de Santa Catarina, aspec- } \\
\text { tos bioéticos relacionados } \\
\text { e propor soluções. }\end{array}$ & $\begin{array}{l}\text { Pesquisa quali- } \\
\text { quantitativa, } \\
\text { descritiva e } \\
\text { transversal }\end{array}$ & $\begin{array}{l}\text { Durante os anos } 2007 \text { a 2012, ocorreu } \\
\text { um considerável avanço das deman- } \\
\text { das judiciais por medicamentos. Res- } \\
\text { gata-se a importância de implantação } \\
\text { de comitês intermunicipais e multipro- } \\
\text { fissionais de bioética, que poderiam } \\
\text { contribuir com melhor aplicação destes } \\
\text { princípios na distribuição dos recursos } \\
\text { para a saúde. }\end{array}$ \\
\hline $\begin{array}{l}\text { Oliveira J. Efetividade do direito à } \\
\text { saúde: uma análise sob um con- } \\
\text { texto de crise financeira e consti- } \\
\text { tucional [Dissertação]. Chapecó: } \\
\text { Campus de Chapecó, Universi- } \\
\text { dade do Oeste de Santa Catari- } \\
\text { na. } 2016\end{array}$ & $\begin{array}{l}\text { Abordar a prestação do } \\
\text { direito constitucional e } \\
\text { social à saúde, analisan- } \\
\text { do o papel do Estado na } \\
\text { efetivação e disponibiliza- } \\
\text { ção deste direito, contexto } \\
\text { de crise financeira e cons- } \\
\text { titucional. }\end{array}$ & $\begin{array}{l}\text { Revisão da } \\
\text { literatura }\end{array}$ & $\begin{array}{l}\text { Para solucionar tais conflitos, surge } \\
\text { como possibilidade a Teoria dos Direi- } \\
\text { tos Fundamentais, defendida por Ro- } \\
\text { bert Alexy, na qual o direito constituci- } \\
\text { onal à saúde deve ser ponderado no } \\
\text { caso concreto. Outra saída apontada } \\
\text { para solucionar o problema existente } \\
\text { na efetivação do direito à Saúde seri- } \\
\text { am as ações coletivas. }\end{array}$ \\
\hline $\begin{array}{l}\text { Santos AO, Delduque MC, } \\
\text { Mendonça AVM. Os discursos } \\
\text { na Audiência Pública da Saúde } \\
\text { e seu impacto nas decisões do } \\
\text { Supremo Tribunal Federal: uma } \\
\text { análise à luz da teoria dos sis- } \\
\text { temas sociais. Saúde e Socie- } \\
\text { dade. } 2015\end{array}$ & $\begin{array}{l}\text { Analisar os discursos e } \\
\text { seu impacto nas decisões } \\
\text { do STF. }\end{array}$ & $\begin{array}{l}\text { Método da aná- } \\
\text { lise de } \\
\text { discurso e } \\
\text { matrizes } \\
\text { comparativas } \\
\text { de decisões } \\
\text { judiciais }\end{array}$ & $\begin{array}{l}\text { A audiência se revelou estratégica e os } \\
\text { discursos teses distintas conforme os } \\
\text { segmentos participantes, demonstran- } \\
\text { do que o direito à saúde não apresenta } \\
\text { significado hegemônico na sociedade. }\end{array}$ \\
\hline
\end{tabular}




\begin{tabular}{|c|c|c|c|}
\hline & O(s) & Método(os) & $\begin{array}{r}\text { Prin } \\
\text { resultados }\end{array}$ \\
\hline $\begin{array}{l}\text { Oliveira LM, Andrade EIG, Mila- } \\
\text { gres M. Ministério Público e polí- } \\
\text { ticas de saúde: implicações de } \\
\text { sua atuação resolutiva e deman- } \\
\text { dista. Revista de Direito Sanitá- } \\
\text { rio. } 2015\end{array}$ & $\begin{array}{l}\text { Identificar o estado da } \\
\text { arte e definir categorias } \\
\text { que orientam o trabalho, } \\
\text { notadamente os conceitos } \\
\text { de MP resolutivo e MP } \\
\text { demandista. }\end{array}$ & $\begin{array}{l}\text { Revisão da } \\
\text { literatura }\end{array}$ & $\begin{array}{l}\text { Verifica-se que a atuação resolutiva, } \\
\text { forma mais adequada para a efetiva- } \\
\text { ção do direito à saúde, é o modelo } \\
\text { seguido pelo MPMG. O aprimoramento } \\
\text { dessa forma de atuação contribui posi- } \\
\text { tivamente para o êxito do trabalho na } \\
\text { defesa desse direito. }\end{array}$ \\
\hline $\begin{array}{l}\text { Machado TRC. Judicialização da } \\
\text { saúde e contribuições da Teoria } \\
\text { de Justiça de Norman Daniels. } \\
\text { Revista de Direito Sanitário. } 2015\end{array}$ & $\begin{array}{l}\text { Revisão bibliográfica e } \\
\text { teórico de Norman Dani- } \\
\text { els, que propõe uma re- } \\
\text { flexão sobre as necessi- } \\
\text { dades de saúde e modo } \\
\text { como podemos atendê- } \\
\text { las. }\end{array}$ & $\begin{array}{l}\text { Revisão } \\
\text { bibliográfica }\end{array}$ & $\begin{array}{l}\text { A busca por atendimento das necessi- } \\
\text { dades de saúde, por meio de qualquer } \\
\text { um dos três poderes, demanda uma } \\
\text { reflexão sobre quais políticas públicas } \\
\text { devem ser repensadas e que vise a } \\
\text { melhor atender às necessidades da } \\
\text { população, não sendo uma simples } \\
\text { avaliação de custo-benefício. }\end{array}$ \\
\hline $\begin{array}{l}\text { Neto OB. A jurisprudência dos } \\
\text { tribunais superiores e o direito à } \\
\text { saúde-evolução rumo à raciona- } \\
\text { lidade. Revista de Direito Sanitá- } \\
\text { rio. } 2015\end{array}$ & $\begin{array}{l}\text { Estudar a posição adota- } \\
\text { da pelo STF e STJ acerca } \\
\text { do direito à saúde, medi- } \\
\text { ante análise da jurispru- } \\
\text { dência das cortes. }\end{array}$ & $\begin{array}{l}\text { Técnicas de } \\
\text { pesquisa } \\
\text { jurisprudencial e } \\
\text { pesquisa } \\
\text { bibliográfica e } \\
\text { documental }\end{array}$ & $\begin{array}{l}\text { O STF e o STJ, chamados a respon- } \\
\text { der sobre essas demandas, oscilaram } \\
\text { sua jurisprudência entre dois extremos } \\
\text { até chegarem a um equilíbrio. }\end{array}$ \\
\hline $\begin{array}{l}\text { Mapelli R. Judicialização da saú- } \\
\text { de e políticas públicas: assistên- } \\
\text { cia farmacêutica, integralidade e } \\
\text { regime jurídico-constitucional do } \\
\text { SUS [Tese]. Universidade de } \\
\text { São Paulo; } 2015\end{array}$ & $\begin{array}{l}\text { Análise da CF, legislação } \\
\text { sanitária e pesquisa re- } \\
\text { trospectiva das ações } \\
\text { judiciais de medicamen- } \\
\text { tos, insumos terapêuticos } \\
\text { e produtos de interesse à } \\
\text { saúde. }\end{array}$ & $\begin{array}{l}\text { Tese de } \\
\text { doutorado }\end{array}$ & $\begin{array}{l}\text { É necessário garantir o atendimento } \\
\text { das demandas individuais, com ingres- } \\
\text { so na rede pública e segundo os pro- } \\
\text { tocolos clínicos e relações de medica- } \\
\text { mentos, evitando-se ao máximo a } \\
\text { banalização do caminho judicial. }\end{array}$ \\
\hline $\begin{array}{l}\text { Delduque MC, Castro EV. A } \\
\text { mediação sanitária como alterna- } \\
\text { tiva viável à judicialização das } \\
\text { políticas de saúde no Brasil. } \\
\text { Saúde em Debate. } 2015\end{array}$ & $\begin{array}{l}\text { Discutir sobre o instituto } \\
\text { da mediação. }\end{array}$ & $\begin{array}{l}\text { Revisão da } \\
\text { literatura }\end{array}$ & $\begin{array}{l}\text { A mediação pode amenizar as contro- } \\
\text { vérsias que geram a judicialização. }\end{array}$ \\
\hline $\begin{array}{l}\text { Magalhães ASF. Atuação do } \\
\text { Poder Judiciário do Distrito Fed }\end{array}$ & $\begin{array}{l}\text { Analisar ações judiciais } \\
\text { que solicitava medica- }\end{array}$ & $\begin{array}{l}\text { Pesquisa quali- } \\
\text { quantitativa }\end{array}$ & $\begin{array}{l}\text { O posicionamento do TJDFT costuma } \\
\text { ser a favor do fornecimento desses }\end{array}$ \\
\hline
\end{tabular}


Cuadernos Iberomericanos

de Derecho Sanitario

\begin{tabular}{|c|c|c|c|}
\hline $\begin{array}{l}\text { Autores, título, } \\
\text { periódico e ano }\end{array}$ & Objetivo(s) & Método(os) & $\begin{array}{l}\text { Principais } \\
\text { resultados encontrados }\end{array}$ \\
\hline $\begin{array}{l}\text { ral no fornecimento de medica- } \\
\text { mentos não padronizados no } \\
\text { SUS. Cadernos lbero- } \\
\text { Americanos de Direito Sanitário. } \\
2015\end{array}$ & $\begin{array}{l}\text { mentos não padronizados } \\
\text { no SUS, Distrito Federal, } \\
2014 .\end{array}$ & & $\begin{array}{l}\text { fármacos, verificando-se a grande } \\
\text { prevalência de liminares deferidas. }\end{array}$ \\
\hline $\begin{array}{l}\text { Machado TRC. Judicialização da } \\
\text { saúde: analisando a audiência } \\
\text { pública no Supremo Tribunal } \\
\text { Federal. Revista Bioética. } 2014\end{array}$ & $\begin{array}{l}\text { Analisar a audiência pú- } \\
\text { blica de } 2009 \text { à luz do } \\
\text { referencial teórico de } \\
\text { Nancy Fraser. }\end{array}$ & $\begin{array}{l}\text { Análise } \\
\text { exploratória }\end{array}$ & $\begin{array}{l}\text { Percebe-se a importância do debate } \\
\text { sobre necessidades na área de saúde, } \\
\text { incluindo o aspecto da judicialização, } \\
\text { que busque avançar na definição e na } \\
\text { satisfação das necessidades dos seto- } \\
\text { res sociais. }\end{array}$ \\
\hline $\begin{array}{l}\text { Massáu GC, Bainy AK. O impac- } \\
\text { to da judicialização da saúde na } \\
\text { comarca de Pelotas. Revista de } \\
\text { Direito Sanitário. } 2014\end{array}$ & $\begin{array}{l}\text { Desvelar impacto da judi- } \\
\text { cialização da saúde na } \\
\text { comarca de Pelotas. }\end{array}$ & $\begin{array}{l}\text { Análise crítica e } \\
\text { contextual }\end{array}$ & $\begin{array}{l}\text { A realocação de recursos para a saú- } \\
\text { de, que haviam sido destinados a ou- } \\
\text { tras demandas, traz óbvio e latente } \\
\text { prejuízo a essas "áreas" da despesa } \\
\text { pública. }\end{array}$ \\
\hline $\begin{array}{l}\text { Mazza FF, Mendes AN. Deci- } \\
\text { sões judiciais e orçamento: um } \\
\text { olhar sobre a saúde pública. } \\
\text { Revista de Direito Sanitário. } 2014\end{array}$ & $\begin{array}{l}\text { Questionar o posiciona- } \\
\text { mento do STF, por acór- } \\
\text { dãos direito à saúde e } \\
\text { orçamento público. }\end{array}$ & $\begin{array}{l}\text { Pesquisas } \\
\text { bibliográfica e } \\
\text { documental }\end{array}$ & $\begin{array}{l}\text { O Poder Judiciário deve observar a } \\
\text { teoria da reserva do possível, buscan- } \\
\text { do uma posição de equilíbrio e racio- } \\
\text { nalidade a partir de sua aplicação. }\end{array}$ \\
\hline $\begin{array}{l}\text { D'espíndula TCAS. Judicializa- } \\
\text { ção da medicina no acesso a } \\
\text { medicamentos: reflexões bioéti- } \\
\text { cas. Revista Bioética (Impressa). } \\
2013\end{array}$ & $\begin{array}{l}\text { Apresentar pontos da } \\
\text { bioética, mediante revisão } \\
\text { bibliográfica. }\end{array}$ & $\begin{array}{l}\text { Revisão } \\
\text { bibliográfica }\end{array}$ & $\begin{array}{l}\text { A judicialização da medicina vem to- } \\
\text { mando cada vez mais vulto. A bioética, } \\
\text { multidisciplinar, pode sugerir algumas } \\
\text { soluções. As decisões do Judiciário } \\
\text { deveriam contemplar a complexidade } \\
\text { da vida humana, não apenas medica- } \\
\text { mentos. }\end{array}$ \\
\hline $\begin{array}{l}\text { Nepomuceno MAS, Bellato R, } \\
\text { Araújo LFS, Mufato LF. O campo } \\
\text { jurídico na garantia do direito à } \\
\text { saúde. Revista de Direito Sanitá- } \\
\text { rio. } 2013\end{array}$ & $\begin{array}{l}\text { Compreender como deci- } \\
\text { sões do Judiciário afetam } \\
\text { o cotidiano de cuidados } \\
\text { com a saúde de uma } \\
\text { família que vivencia a } \\
\text { condição crônica de uma } \\
\text { doença. }\end{array}$ & $\begin{array}{l}\text { Revisão da } \\
\text { literatura }\end{array}$ & $\begin{array}{l}\text { Se o Judiciário adotasse postura de } \\
\text { acolhimento às necessidades amplia- } \\
\text { das diminuiria, em grande escala, o } \\
\text { movimento de judicialização da saúde. }\end{array}$ \\
\hline Pinto CDBS. Demandas judiciais & Caracterizar o cenário da & Estudo & É necessária a conscientização dos \\
\hline
\end{tabular}


Cuadernos Iberomericanos

de Derecho Sanitario

Autores, título,
periódico e ano

por medicamentos e estratégias de gestão da assistência farmacêutica em municípios do Estado de Mato Grosso do Sul [Tese]. Escola Nacional de Saúde Pública Sergio Arouca. 2013.

Travassos DV, Ferreira RC, Vargas AMD, Moura RNV, Concei-

ção EMA, Marques DF, Ferreira EF. Judicialização da Saúde: um estudo de caso de três tribunais brasileiros. Ciência \& Saúde Coletiva. 2013

Marçal KKS. A Judicialização da Assistência Farmacêutica: o caso Pernambuco em 2009 e 2010 [Tese]. Centro de Pesquisas Aggeu Magalhães. 2012 Soares JCRS, Deprá AS. Ligações perigosas: indústria farmacêutica, associações de pacientes e as batalhas judiciais por acesso a medicamentos. Physis: Revista de Saúde Coletiva. 2012 Pepe VLE, Figueiredo TA, Simas L, Osorio-de-Castro CGS, Ventura M. A judicialização da saúde e os novos desafios da gestão da assistência farmacêutica. Ciência \& Saúde Coletiva. 2010 Ventura M, Simas L, Pepe VLE. Judicialização da saúde, acesso à justiça ea efetividade do direito à saúde. Physis: Revista de Saúde Coletiva. 2010
Objetivo(s)

udicialização em municípios do Mato Grosso do Sul, analisando consequências sobre a gestão da assistência farmacêutica.

Analisar características

das ações impetradas contra o SUS e que tiveram recurso em segunda instância quanto aos resultados dessas ações.

Analisar o fenômeno da judicialização da política de assistência farmacêutica de Pernambuco.

Trazer novos elementos para o debate sobre a judicialização da saúde e acesso a medicamentos. Compreender o uso da via judicial para fornecimento de medicamentos, a relação deste mecanismo com a gestão da $\mathrm{AF}$ no SUS.

\section{Analisar vínculos entre} acesso à justiça e a efetividade dos aspectos do direito à saúde: 0 acesso aos medicamentos.

\section{Método(os)}

descritivo trans- médicos, peças fundamentais no proversal

O

\begin{tabular}{|l|l} 
Estudo & O \\
transversal & di \\
& pot
\end{tabular}
cesso, no que se refere à padronização dos itens pelo Ministério da Saúde e do uso racional de medicamentos.

O usuário tem buscado garantir seu direito à saúde, recorrendo ao próprio poder público para a propositura da ação, mas percebe-se uma diferença de postura jurídica entre os tribunais avaliados.

\section{Abordagem}

quantitativa e qualitativa

O fenômeno tem apresentado comportamento estável em relação às causas, apesar do sempre crescente aumento do número de processos.

\section{Levantamento} bibliográfico

Existem questões urgentes para o debate político sobre o acesso aos medicamentos, que não pode ignorar o peso das interferências causadas pela farmaindústria.

\section{Revisão e}

análise das

pesquisas

disponíveis

É possível formular estratégias e ações potencialmente mais efetivas para a melhoria do acesso à saúde e, também, para a redução da demanda judicial.

As demandas judiciais não podem ser consideradas como principal instrumento deliberativo na gestão da AF no SUS, mas admitidas como um elemento importante na tomada de decisão 
Cuadernos Iberomericanos

de Derecho Sanitario

\begin{tabular}{|c|c|c|c|}
\hline $\begin{array}{l}\text { Autores, título, } \\
\text { periódico e ano }\end{array}$ & Objetivo(s) & Método(os) & $\begin{array}{l}\text { Principais } \\
\text { resultados encontrados }\end{array}$ \\
\hline & & & $\begin{array}{l}\text { dos gestores e na melhoria do acesso } \\
\text { aos medicamentos. }\end{array}$ \\
\hline $\begin{array}{l}\text { Oliveira JAD. Demandas jurídi- } \\
\text { cas por coberturas assistenciais: } \\
\text { estudo de caso: CASSI [Tese]. } \\
\text { São Paulo: Universidade de São } \\
\text { Paulo. } 2010\end{array}$ & $\begin{array}{l}\text { Analisar o montante e } \\
\text { motivos das ações judici- } \\
\text { ais relacionadas às cober- } \\
\text { turas assistenciais. }\end{array}$ & $\begin{array}{l}\text { Recorte } \\
\text { temporal de } \\
1998 \text { a } 2009\end{array}$ & $\begin{array}{l}\text { Evolução crescente do número de } \\
\text { ações; o fato de a Bahia possuir } 9,5 \% \\
\text { da população assistida e responder } \\
\text { por } 33,4 \% \text { das ações totais. }\end{array}$ \\
\hline $\begin{array}{l}\text { Gontijo GDA. Judicialização do } \\
\text { direito à saúde. Revista Médica } \\
\text { de Minas Gerais. } 2010\end{array}$ & $\begin{array}{l}\text { Refletir sobre paradoxos } \\
\text { da interferência do Poder } \\
\text { Judiciário como novo } \\
\text { meio de efetivação do } \\
\text { direito à saúde, analisan- } \\
\text { do conflito entre necessi- } \\
\text { dade de efetivação da } \\
\text { tutela de interesses indivi- } \\
\text { duais ou coletivos. }\end{array}$ & $\begin{array}{l}\text { Revisão da } \\
\text { literatura }\end{array}$ & $\begin{array}{l}\text { A implementação de políticas públicas } \\
\text { vincula-se a prestações materiais } \\
\text { submetidas à dotação orçamentária } \\
\text { dos entes federativos; deve-se propici- } \\
\text { ar mais eficácia às decisões políticas, } \\
\text { salvaguardando as necessidades cole- } \\
\text { tivas. }\end{array}$ \\
\hline
\end{tabular}

Fonte: Dados obtidos de artigos segundo a metodologia de revisão do estudo.

\section{Considerações finais}

Apesar do constante aumento das ações judiciais, em busca da efetivação do direito à saúde, diferentes propostas são sugeridas para uma possível racionalização da judicialização da saúde:

- Em termos preventivos, as propostas extrajudiciais, formais ou informais, são recomendadas como primeira opção pela oportunidade de solucionar os conflitos sem ingressar pela via judicial.

- A conscientização de juízes, profissionais e população se torna premente para reversão deste processo e as decisões baseadas em evidências científicas e protocolos de tratamento estabelecidos pelo SUS poderão ser utilizados pelos magistrados como o fiel da balança. Por outro lado, as mudanças administrativas no SUS representariam uma possibilidade prévia de diálogo e mediação em que os usuários insatisfeitos pudessem recorrer sem a interferência do Poder Judiciário.

- O diálogo entre os atores sociais envolvidos na judicialização da saúde é uma recomendação frequente entre os autores e pode ser alcançado com diferentes arranjos, 
promovendo a capacitação mútua, a constante atualização e possíveis soluções compartiIhadas e inovadoras. Assim, iniciativas locais que mobilizem os setores envolvidos como as instituições políticas, jurídicas, sociais e dos profissionais da saúde, são igualmente esperadas, visto que não existe uma única solução, mas a necessidade de um contínuo processo de integração entre esses setores.

Espera-se que a elucidação das diversas estratégias utilizadas na redução das demandas em saúde possa contribuir para a concretização das políticas públicas planejadas. Como o gestor de serviços de saúde encontra-se na base desse processo ascendente e sofre diretamente as consequências das decisões judiciais, não poderá se abster deste conhecimento e com uma atuação consciente e efetiva poderá certamente contribuir com novas propostas para manutenção do direito à saúde.

\section{Referências}

1. Brasil. Constituição da República Federativa do Brasil, 8 de outubro de 1988. Brasília: Senado Federal, 1988.

2. Brasil. Ministério da Saúde. Lei no 8.080 , de 19 de setembro de 1990. Dispõe sobre as condições para a promoção, proteção e recuperação da saúde, a organização e o funcionamento dos serviços correspondentes e dá outras providências. Diário Oficial da União da República Federativa do Brasil. (20 set. 1990).

3. Luz RGAM. Judicialização do Orçamento Público: Repercussões da Ingerência do Judiciário nas Contas Públicas e no Planejamento da Gestão Estatal em Decisões Referentes à Saúde. Publicações da Escola da AGU. 2013, out.; 2(30): 189-212.

4. Oliveira MRM, Delduque MC, Sousa MF, Mendonça AVM. Judicialização da saúde: para onde caminham as produções científicas? Saúde em Debate. 2015, abr./jun.; 39(105): 525535.

5. Santos IS. A solução para o SUS não é um Brazilcare. Revista Eletrônica de Comunicação. Informação e Inovação em Saúde. 2016, set.; 10(3).

6. Vieira FS. Ações judiciais e direito à saúde: reflexão sobre a observância aos princípios do SUS. Revista de Saúde Pública. 2008, abr.; 42(2): 365-369.

7. Baptista TWF, Machado CV, Lima LD. Responsabilidade do Estado e direito à saúde no Brasil: um balanço da atuação dos Poderes. Ciência \& Saúde Coletiva. 2009, mai./jun.; 14(3): 829-839. 
8. Lima FRS. Racionalidade dos direitos sociais sob a óptica da constituição como acoplamento estrutural entre os sistemas jurídico e político. Revista da Faculdade de Direito da UFG. 2010, jan./jun.;34(1): 88-97.

9. Machado FRS, Dain S. A Audiência Pública da Saúde: questões para a judicialização e para a gestão de saúde no Brasil. Revista de Administração Pública. 2012, jul./ago.; 46(4): 1017-1036.

10. Cunha Filho MC. Qual é a justiça da justiça brasileira? Uma análise das decisões do supremo tribunal federal em matéria de direito à saúde à luz das teorias políticas de R. Nozick, J. Rawls e R. Dworkin. Revista Direito e Práxis. 2013, abr./nov.; 4(7): 172-195.

11. Sartori Junior A, Leivas PGC, Souza MV, Krug BC, Balbinotto G, Schwartz IVD. Judicialização do acesso ao tratamento de doenças genéticas raras: a doença de Fabry no Rio Grande do Sul. Ciência \& Saúde Coletiva. 2012, out.; 17(10): 2717-2728.

12. Ventura M, Simas L, Pepe VLE. Judicialização da saúde, acesso à justiça e a efetividade do direito à saúde. Physis: Revista de Saúde Coletiva. 2010, 20(1): 77-100.

13. Asensi F. Responsabilidade Solidária dos Entes da Federação e" Efeitos Colaterais" no Direito à Saúde. Revista de Direito Sanitário. 2016 nov. 2015 /fev. 2016, 16(3): 145-156.

14. Dallari SG, Maggio MP. A efetivação jurídico-política do direito à saúde no Supremo Tribunal Federal: a referência paradigmática da sl 47-agr/pe. Revista de Direito Sanitário. 2017, nov. / fev.; 17(3): 58-76.

15. Mazza FF, Mendes AN. Decisões judiciais e orçamento: um olhar sobre a saúde pública. Revista de Direito Sanitário. 2014, nov. 2013/ fev. 2014; 14(3): 42-65.

16. Arruda SC. Análise sobre a judicialização da saúde no estado de Mato Grosso no período de 2011-2012. Cadernos Ibero-Americanos de Direito Sanitário. 2017, jan./mar; 6(1): 86-111.

17. Asensi F, Pinheiro R. Judicialização da saúde e Diálogo Institucional: A experiência de Lages (SC). Revista de Direito Sanitário. 2016, jul./out.; 17(2): 48-65.

18. Barreto JL, Pereira MT, Guimarães MCJ, Penaforte TR, Formigli VLA. Perfil das demandas judiciais por medicamentos em municípios do estado da Bahia. Revista Baiana de Saúde Pública. 2013, jul./set.;37(3): 536-552.

19. Massáu GC, Bainy AK. O impacto da judicialização da saúde na comarca de Pelotas. Revista de Direito Sanitário. 2014, jul./out.; 15(2): 46-65.

20. Nogueira JL, Carvalho L, Dadalto L. Parcerias entre Universidades e Poder Judiciário: experiência de Minas Gerais. Cadernos Ibero-Americanos de Direito Sanitário. 2017, jan. / mar.; 6(1): 55-71. 
21. Zago B, Swiech LM, Bonamigo EL, Schlemper Junior BR. Aspectos bioéticos da judicialização da saúde por medicamentos em 13 municípios no Meio-Oeste de Santa Catarina, Brasil. Acta Bioethica. 2016, 22(2): 293-302.

22. Conselho Nacional de Justiça. Justiça pesquisa: Judicialização da saúde no Brasil. Brasília; 2015. 142p.

23. Thiry-Cherques HR. Max Weber: o processo de racionalização e o desencantamento do trabalho nas organizações contemporâneas. Rev. Adm. Pública. 2009, ago.; 43(4): 897918.

24. Duarte CS, Braga PVB. A Utilização dos Protocolos Clínicos e Diretrizes Terapêuticas e a Racionalização da Judicialização do Direito à Saúde. Revista de Direito Sanitário. 2015, mar./jun. 18(1): 171-190.

25. Mapelli R. Judicialização da saúde e políticas públicas: assistência farmacêutica, integralidade e regime jurídico-constitucional do SUS [Tese]. São Paulo: Universidade de São Paulo; 2015.

26. Mendes KDS, Silveira RCCP, Galvão CM. Revisão integrativa: método de pesquisa para a incorporação de evidências na saúde e na enfermagem. Texto Contexto Enferm. 2008, 17(4): 758-764.

27. Oliveira J. Efetividade do direito à saúde: uma análise sob um contexto de crise financeira e constitucional [Dissertação]. Chapecó: Campus de Chapecó, Universidade do Oeste de Santa Catarina; 2016.

28. Machado TRC. Judicialização da saúde e contribuições da Teoria de Justiça de Norman Daniels. Revista de Direito Sanitário. 2015, jul./out.; 16(2): 52-76.

29. Delduque MC, Castro EV. A mediação sanitária como alternativa viável à judicialização das políticas de saúde no Brasil. Saúde em Debate. 2015, fev./jun.; 39: 506-513.

30. D'espíndula TCAS. Judicialização da medicina no acesso a medicamentos: reflexões bioéticas. Revista Bioética (Impressa). 2013; 21(3): 438-447.

31. Gontijo GDA. Judicialização do direito à saúde. Revista Médica de Minas Gerais. 2010, 20(4): 606-611.

32. Machado TRC. Judicialização da saúde: analisando a audiência pública no Supremo Tribunal Federal. Revista Bioética. 2014, set./dez.; 22(3): 561-568.

33. Magalhães ASF. Atuação do Poder Judiciário do Distrito Federal no fornecimento de medicamentos não padronizados no SUS. Cadernos Ibero-Americanos de Direito Sanitário. 2015, jul./set.; 4(3): 3-24.

34. Marçal KKS. A Judicialização da Assistência Farmacêutica: o caso Pernambuco em 2009 e 2010 [Tese]. Recife: Centro de Pesquisas Aggeu Magalhães; 2012. 
35. Nepomuceno MAS, Bellato R, Araújo LFS, Mufato LF. O campo jurídico na garantia do direito à saúde. Revista de Direito Sanitário. 2013, jul./out.; 14(2): 119-136.

36. Neto $\mathrm{OB}$. A jurisprudência dos tribunais superiores e o direito à saúde: evolução rumo à racionalidade. Revista de Direito Sanitário. 2015, mar./jun.; 16(1): 87-111.

37. Oliveira LM, Andrade EIG, Milagres M. Ministério Público e políticas de saúde: implicações de sua atuação resolutiva e demandista. Revista de Direito Sanitário. 2015, nov. 2014/ fev. 2015; 15(3): 142-161.

38. Oliveira JAD. Demandas jurídicas por coberturas assistenciais: estudo de caso: CASSI [Tese]. São Paulo: Universidade de São Paulo; 2010.

39. Pepe VLE, Figueiredo TA, Simas L, Osorio-de-Castro CGS, Ventura M. A judicialização da saúde e os novos desafios da gestão da assistência farmacêutica. Ciência \& Saúde Coletiva. 2010, ago.; 15(5): 2405-2414

40. Pinheiro LKT, Melo PF. O impacto financeiro da judicialização da saúde demonstrado através de um modelo econômico teórico. In: Anais do XI Encontro São Paulo, 2014. São Paulo.

41. Pinto CDBS. Demandas judiciais por medicamentos e estratégias de gestão da assistência farmacêutica em municípios do Estado de Mato Grosso do Sul [Tese]. Rio de Janeiro: Escola Nacional de Saúde Pública Sergio Arouca; 2013.

42. Santos AO, Delduque MC, Mendonça AVM. Os discursos na Audiência Pública da Saúde e seu impacto nas decisões do Supremo Tribunal Federal: uma análise à luz da teoria dos sistemas sociais. Saúde e Sociedade. 2015, 24 Supl 1: 184-192.

43. Silva Junior GB, Dias ER. Avaliação da satisfação dos usuários de um serviço de saúde público-privado no nordeste do Brasil e a judicialização da saúde. Revista de Direito Sanitário. 2016, jul./out.; 17(2): 13-29.

44. Soares JCRS, Deprá AS. Ligações perigosas: indústria farmacêutica, associações de pacientes e as batalhas judiciais por acesso a medicamentos. Physis: Revista de Saúde Coletiva. 2012, 22(1): 311-329.

45. Travassos DV, Ferreira RC, Vargas AMD, Moura RNV, Conceição EMA, Marques DF, Ferreira EF. Judicialização da Saúde: um estudo de caso de três tribunais brasileiros. Ciência \& Saúde Coletiva. 2013, nov.; 18(11): 3419-3429.

46. Verbicaro LP, Santos ACV. A necessidade de parâmetros para a efetivação do direito à saúde: a judicialização do acesso ao hormônio do crescimento no estado do Pará. Revista de Direito Sanitário. 2017, mar.; 17(3): 185-211. 
Cadernos Ibero-Americanos

de Direito Sanitário

Cuadernos Iberomericanos

de Derecho Sanitario

Recebido em: 07/08/18

Como citar esse artigo:

Aprovado em: 11/04/19

Dal Moro CC, Dal Moro L, Randow R, Zocratto KBF. Judicialização da saúde: propostas de racionalização. Cadernos Ibero-Americanos de Direito Sanitário. 2019 jan./mar.; 8(1): 119-140. 